This item was submitted to Loughborough's Research Repository by the author.

Items in Figshare are protected by copyright, with all rights reserved, unless otherwise indicated.

\title{
Impact of panic attacks on bronchoconstriction and subjective distress in asthma patients with and without panic disorder
}

PLEASE CITE THE PUBLISHED VERSION

https://doi.org/10.1097/PSY.0000000000000443

\section{PUBLISHER}

(C) American Psychosomatic Society. Published by Lippincott, Williams \& Wilkins

\section{VERSION}

AM (Accepted Manuscript)

\section{PUBLISHER STATEMENT}

This work is made available according to the conditions of the Creative Commons Attribution-NonCommercialNoDerivatives 4.0 International (CC BY-NC-ND 4.0) licence. Full details of this licence are available at: https://creativecommons.org/licenses/by-nc-nd/4.0/

\section{LICENCE}

CC BY-NC-ND 4.0

\section{REPOSITORY RECORD}

Boudreau, Maxine, Simon L. Bacon, Nicola Paine, Andre Cartier, Barbara Trutschnigg, Alexandre Morizio, and Kim L. Lavoie. 2017. "Impact of Panic Attacks on Bronchoconstriction and Subjective Distress in Asthma Patients with and Without Panic Disorder". figshare. https://hdl.handle.net/2134/34445. 
Asthma, panic disorder and $\mathrm{CO}_{2}$

Impact of panic attacks on bronchoconstriction and subjective distress in asthma patients with and without panic disorder

Maxine Boudreau, $\mathrm{PhD}^{1,2,4}$, Simon L. Bacon, $\mathrm{PhD}^{1,3,4}$, Nicola J Paine, $\mathrm{PhD}^{1,3}$, André Cartier, $\mathrm{MD}^{4}$, Barbara Trutschnigg, MSc ${ }^{1,4}$, Alexandre Morizio, $\mathrm{MSc}^{1,3}, \&$ Kim L. Lavoie, $\mathrm{PhD}^{1,2,4}$

${ }^{1}$ Montreal Behavioural Medicine Centre, Hôpital du Sacré-Cœur de Montréal, 5400 Gouin West, Montréal, Québec, H4J 1C5, Canada

${ }^{2}$ Department of Psychology, University of Quebec at Montreal (UQAM), 100 Sherbrooke West, Montreal, Quebec, H3C 3P8, Canada

${ }^{3}$ Department of Exercise Science, Concordia University, 7141 Sherbrooke St. West, Montreal, Quebec, H4B 1R6, Canada

${ }^{4}$ Research Center, Hôpital du Sacré-Coeur de Montréal, Montréal, Québec, Canada

All authors have no conflicts of interest.

Corresponding Author: Kim L. Lavoie, PhD, Montreal Behavioral Medicine Centre, Hôpital du Sacré-Cœur de Montréal - a University of Montréal affiliated hospital, 5400 Gouin West, Montréal, Québec, H4J 1C5, Canada. Tel: 514-338-2222 (3709); Fax: 514-338-3123.

Email: k-lavoie@crhsc.rtss.qc.ca

Running Head: Asthma, panic disorder and $\mathrm{CO}_{2}$

Abstract word count: 250

Total word count: 4645

References: 59 
Asthma, panic disorder and $\mathrm{CO}_{2}$

\section{LIST OF ABREVIATIONS}

$\mathrm{ACQ}=$ Asthma Control Questionnaire

ADIS-IV = Anxiety Disorders Interview Schedule for DSM-IV

$\mathrm{BMI}=$ Body Mass Index

$\mathrm{CO}_{2}=$ Carbon Dioxide

DBP $=$ Diastolic Blood Pressure

DSM-IV-TR $=$ Diagnostic and Statistical Manual of Mental Disorders, $4^{\text {th }}$ edition, text revised

DSM-5 = Diagnostic and Statistical Manual of Mental Disorders, $5^{\text {th }}$ edition

$\mathrm{FEV}_{1}=$ Forced Expiratory Volume in one second

FVC $=$ Forced Vital Capacity

GLM = General Linear Model

HR $=$ Heart Rate

ICS = Inhaled Corticosteroid

MCT $=$ Methacholine Challenge Test

$\mathrm{PA}=$ Panic Attack

$\mathrm{PC}_{20}=$ Provocative Concentration of methacholine

$\mathrm{PD}=$ Panic Disorder

PSS $=$ Panic Symptom Scale

$\mathrm{RR}=$ Respiratory Rate

SBP $=$ Systolic Blood Pressure

SD-VAS = Subjective Distress Visual Analogue Scale

$\mathrm{VCO}_{2}=$ Carbon Dioxide Production

$\mathrm{VE}=$ Minute Ventilation

$\mathrm{VO}_{2}=$ Oxygen Uptake 
Asthma, panic disorder and $\mathrm{CO}_{2}$

VT $=$ Tidal Volume 
Asthma, panic disorder and $\mathrm{CO}_{2}$

\section{ABSTRACT}

Background: Panic disorder (PD) is common among asthmatics and is associated with worse asthma outcomes. This may occur due to psychophysiological factors or to cognitive/affective factors. This study evaluated the impact of panic attacks (PAs) on bronchoconstriction and subjective distress in asthmatics with and without PD. Methods: A total of 25 asthmatics (15 with PD who had a PA [PD/PA], 10 without PD who didn't have a PA [noPD/noPA]) were recruited from an outpatient clinic. They underwent a panic challenge (one vital capacity inhalation of $35 \%$ carbon dioxide $\left[\mathrm{CO}_{2}\right]$ ) and completed the Panic Symptom Scale (PSS), the Subjective Distress Visual Analogue Scale (SD-VAS) and the Borg Scale before and after $\mathrm{CO}_{2}$. Forced expiratory volume in one second $\left(\mathrm{FEV}_{1}\right)$ was assessed pre and post $\mathrm{CO}_{2}$; respiratory (i.e., $\mathrm{CO}_{2}$ production $\left[\mathrm{VCO}_{2}\right]$, minute ventilation [VE], tidal volume [VT]) were continuously recorded, and physiological measures (i.e., systolic and diastolic blood pressure [SBP/DBP]), every two minutes. Results: Analyses adjusting for age, sex, and provocative concentration of methacholine revealed no significant differences between groups in $\mathrm{FEV}_{1}$ change after $\mathrm{CO}_{2}$ inhalation $(\mathrm{F}(1,23)<0.01, \mathrm{p}=.961)$. However, $\mathrm{PD} / \mathrm{PA}$ patients reported more panic $(\mathrm{F}(1,22)=18.10, \mathrm{p}<.001)$, anxiety $(\mathrm{F}(1,22)=21.93, \mathrm{p}<.001)$, worry $(\mathrm{F}(1,22)=26.31, \mathrm{p}<.001)$ and dyspnea $(\mathrm{F}(1,22)=4.68, \mathrm{p}=.042)$, and exhibited higher levels of $\mathrm{VCO}_{2}(\mathrm{~F}(1,2843)=5.89, \mathrm{p}=.015)$, $\operatorname{VE}(\mathrm{F}(1,2844)=4.48, \mathrm{p}=.034)$, and $\operatorname{VT}(\mathrm{F}(1,2844)=4.62, \mathrm{p}=.032)$ after the $\mathrm{CO}_{2}$ challenge, compared to noPD/noPA patients. Conclusions: Results, presented as hypothesis generating, suggest that asthmatics with PD/PA exhibit increased panic-like anxiety, breathlessness and a respiratory pattern consistent with hyperventilation that was not linked to statistically significant drops in bronchoconstriction. 
Asthma, panic disorder and $\mathrm{CO}_{2}$

Keywords: Asthma, bronchoconstriction, $\mathrm{CO}_{2}$, panic disorder, panic attack, anxiety. 
Asthma, panic disorder and $\mathrm{CO}_{2}$

\section{INTRODUCTION}

During the last decade, studies have observed a high prevalence of anxiety disorders in asthma populations, with a point prevalence of up to $34 \%$ in adults (1). Panic disorder (PD) has been shown to be the most prevalent anxiety disorder in individuals with asthma, with rates ranging from $6.5-24 \%$, which is up to 10 times the rate observed in the general population (1-5). PD is characterized by sudden, recurrent panic attacks (PAs), which are episodes of intense fear or discomfort associated with at least four cognitive (e.g., fear of losing control, fear of dying) and/or physiological (e.g., shortness of breath, dizziness, chest tightness) symptoms (6). PD has also been associated with worse asthma outcomes, including increased physician visits, emergency visits, rescue medication use, and reduced asthma-related quality of life (7-9). The link between PD and worse asthma outcomes is quite robust and, although the mechanisms remain poorly understood, PAs may be the pathway through which they are linked.

Several theories have been developed to explain the relationship between asthma and PD and how this comorbidity may lead to worse asthma outcomes. In general, these theories may be categorized as "psychophysiological" or "cognitive/affective". The "psychophysiological" theory postulates that PD leads to worse asthma outcomes through direct physiological pathways, notably via anxiety (specifically panic)-induced increases in autonomic arousal leading to increased parasympathetic drive, resulting in bronchial hyper-responsiveness and obstruction (10, 11). For example, a study from Hibbert and colleagues (1988) monitored transcutaneous $\mathrm{PCO}_{2}$ in patients with asthma and found that hyperventilation precedes exacerbation of asthma, which suggests that panic may trigger an asthma attack through hyperventilation and airway cooling. In contrast, the "cognitive/affective" theory postulates that PD leads to worse asthma outcomes due to a tendency to misattribute panic-related anxiety symptoms as asthma symptoms and/or to catastrophize symptoms of breathlessness that signal a possible "asthma" attack $(12,13)$. This 
Asthma, panic disorder and $\mathrm{CO}_{2}$

may result in increased rescue medication use and health care seeking in the absence of true airway obstruction (7). For example, a study from Van Peski-Oosterbaan and colleagues (1996) found no differences in pulmonary function in patients with asthma and with (and without) PD during induced bronchoconstriction, but found that PD patients reported higher levels of breathlessness, which could be due to catastrophisation. Asthma attacks and PAs share several overlapping symptoms, such as shortness of breath, sensations of being smothered, choking, and heightened anxiety (including fears of suffocating/dying). This symptom overlap, and possible symptom confusion (12), may also influence asthma outcomes (7, 8).

Though previous studies have found evidence supporting both theories $(2,10,12)$, results have been inconclusive and no studies to date have directly assessed the impact of PAs on both objective airway obstruction and subjective responses in documented asthmatics with PD. One of the most reliable ways to induce a PA in a laboratory setting is through carbon dioxide $\left(\mathrm{CO}_{2}\right)$ inhalation, which has been shown to be both safe and non-invasive (12). A recent systematic review of the efficacy of using $\mathrm{CO}_{2}$ challenges to induce spontaneous PAs in PD patients (without asthma) reported that the vast majority of studies used a standardized protocol of one vital capacity inhalation of $35 \%$ of $\mathrm{CO}_{2}$ (12). Experimental studies have also shown that PD patients are more sensitive to $35 \% \mathrm{CO}_{2}$ inhalation than healthy subjects and those with other psychiatric disorders (e.g., generalized anxiety disorder and depression) $(14,15)$ pointing to the specificity of this challenge. We are aware of only one study to date that used $35 \% \mathrm{CO}_{2}$ challenge to induce PAs in patients with a history of respiratory disorders (i.e., asthma and bronchitis), but who did not currently have a respiratory disorder (16). Though this study found no association between PD and increased subjective distress after the panic challenge, it did not measure any physiological (i.e., respiratory) responses, which limits its contribution. It also suffered from additional methodological weaknesses: participants with current respiratory disorders were 
Asthma, panic disorder and $\mathrm{CO}_{2}$

excluded, which limits its generalizability to patients with current asthma diagnoses; and patients were included based on self-reports of previous histories of respiratory disorders, which may be unreliable, non-specific, and introduces the potential for recall bias, particularly among anxious individuals who may over-report asthma (17).

To address these limitations and more comprehensively assess the link between PD and asthma, the present study evaluated the impact of PD and PAs on bronchoconstriction, subjective distress, and physiological responses, in patients with documented asthma. It was hypothesized that asthmatics with PD who had a PA (PD/PA) in response to one vital capacity inhalation of $35 \% \mathrm{CO}_{2}$, would be more likely to exhibit 1) worse objective airway obstruction, 2) worse subjective distress, 3) greater cardiovascular activation, and 4) higher respiratory responses, compared to asthmatics without PD who did not have a PA (noPD/noPA).

\section{METHODS}

\section{Participants}

Patients with physician-diagnosed asthma were recruited between September 2011 to December 2013 from a prospective database of adult asthma and chronic obstructive pulmonary disease patients (RESP - REgistre de données en $\underline{\text { Santé }}$ Pulmonaire). Patients were eligible for the study if they had an asthma diagnosis confirmed by evidence of a positive methacholine challenge test (MCT) (18) performed in our laboratory prior to the experimentation, were aged 18 to 70 years old, and could speak English or French. Patients were excluded if they were current smokers, had any significant medical conditions that were more serious than asthma (e.g., chronic obstructive pulmonary disease), and displayed cognitive or language deficit that would have impaired providing informed consent. Patients in the PD/PA group had to meet Diagnostic and 
Asthma, panic disorder and $\mathrm{CO}_{2}$

Statistical Manual of Mental Disorders, $4^{\text {th }}$ edition, text revised (DSM-IV-TR) criteria for a primary psychiatric diagnosis of PD (19) and had to have a positive PA response to the $\mathrm{CO}_{2}$ challenge (see details in the Measures section); patients in the control group could not meet any DSM-IV-TR criteria for any current or past Axis I psychiatric disorder and could not have a PA response to the $\mathrm{CO}_{2}$ challenge. For those in the PD/PA group, they were excluded if they met criteria for a current Axis I psychiatric disorder that was more severe than PD (e.g., schizophrenia, major depression), which was determined by the ADIS-IV (other anxiety or mood disorder) and/or self-reported or chart evidence of current diagnoses or medication use (psychoses).

Given the above criteria, a total of 94 individuals were eligible to participate in this study (see flow chart of patient inclusion in Figure 1). Of those, 57 declined to participate, which resulted in a sample of 37 patients (39\% participation rate). Twelve patients were excluded from the analyses based on their response to the $\mathrm{CO}_{2}$ challenge (i.e., PD patients who didn't have a PA $(\mathrm{n}=3)$ and no-PD patients who did have a PA $(\mathrm{n}=9))$, yielding a final sample of 25 patients $(15$ PD/PA and 10 noPD/noPA). Written consent was obtained from all participants and the Ethics Committee of the Hôpital du Sacré-Coeur de Montréal approved this project (\#2003-10-198; 2010-95).

\section{Study design and procedure}

This quasi-experimental study was part of a larger research protocol assessing bronchial responsiveness to a $\mathrm{MCT}$ and $\mathrm{CO}_{2}$ panic challenge in asthma patients with and without $\mathrm{PD}$, and some aspects of the design have been previously described (20). As part of a larger study, we demonstrated that asthma patients with PD who underwent a MCT experienced higher levels of subjective distress, but not greater airway responsiveness (bronchoconstriction) than patients 
Asthma, panic disorder and $\mathrm{CO}_{2}$

without PD, suggesting that the observed increased morbidity in asthma patients with PD is more likely due to a catastrophization of bodily symptoms rather than more severe asthma. For both studies, eligible patients were contacted by phone by a trained clinical research assistant to undergo the Anxiety Disorders Interview Schedule for DSM-IV (ADIS-IV) to assess psychiatric disorders. Those who consented presented in the laboratory and completed a screening interview, which included demographic information, as well as medical and asthma history (including the Asthma Control Questionnaire [ACQ]).

On their testing day of the panic challenge study, patients were informed that they would breathe in one vital capacity inhalation of $35 \% \mathrm{CO}_{2}$ (balanced with $65 \%$ oxygen). Patients were told what symptoms they might experience (including shortness of breath and mild dizziness), but that these symptoms, if they occurred, would be temporary (lasting only a few moments) and harmless. In order to minimize anticipatory anxiety, they were not explicitly told they might experience a "panic attack", which is consistent with our previous work (21). Further, patients were told that they would inhale $35 \% \mathrm{CO}_{2}$ or compressed atmospheric air, but would not know which they would receive since the gas mixture was randomly selected in a double-blind fashion (though all patients received $\mathrm{CO}_{2}$ ).

Upon presentation to the laboratory, patients were seated in a comfortable chair and were fitted with a mask that was connected to a gas analyzer (Jaeger Oxycon Pro, Carefusion, Germany), which in turn was connected online to a computer. For the inhalation of the gas mixture, patients were asked to exhale as fully as possible, then take one vital capacity inhalation of the gas, hold it for 4 seconds, and then breathe normally. Serial spirometry assessments (Spirobank G spirometer, Medical International Research, Inc., Italy) were conducted before and for 20 minutes after the inhalation at two minute intervals. Each time, $\mathrm{FEV}_{1}$ was measured twice. For the purposes of this study, only the $\mathrm{FEV}_{1}$ measured right before and right after the inhalation 
Asthma, panic disorder and $\mathrm{CO}_{2}$

were analyzed. $\mathrm{A} \mathrm{CO}_{2}$-induced asthma exacerbation was defined as having a $\geq 10 \%$ drop in their best (i.e., highest) $\mathrm{FEV}_{1}$ post challenge, because this drop has been reported to be the lower limit of clinical significance $(22,23)$. Respiratory responses were assessed by tidal volume [VT], respiratory rate $[\mathrm{RR}], \mathrm{CO}_{2}$ production $\left[\mathrm{VCO}_{2}\right]$, oxygen uptake $\left[\mathrm{VO}_{2}\right]$ and minute ventilation [VE]), which were continuously recorded by the gas analyzer (24). Breath-by-breath recordings of respiratory variables were averaged each 5 seconds and then overall averages per group were analyzed pre and post gas inhalation. In order to evaluate the proximal effect of the $\mathrm{CO}_{2}$ inhalation, only the 3 minute period post inhalation was analyzed, which represents the duration range of the PA including the administration of subjective distress questionnaires. Cardiovascular activation was assessed by heart rate [HR], systolic and diastolic blood pressure [SBP/DBP]) (Datascope Accutorr Plus, New Jersey, USA), which were recorded every two minutes. After the gas inhalation, there was a recovery period of 20 minutes. Dyspnea (Borg Scale), subjective distress (Subjective Distress Visual Analogue Scale [SD-VAS]) and PA assessments (Panic Symptom Scale [PSS]) were administered by a trained $\mathrm{PhD}$ student in clinical psychology before and after the inhalation and prior to spirometry assessment.

\section{MEASURES}

\section{Baseline measures}

\section{Anxiety Disorders Interview Schedule for DSM-IV (ADIS-IV)}

The ADIS-IV (25) is a semi-structured interview typically used to confirm the diagnosis of several psychiatric disorders described in the DSM-IV, including mood and anxiety disorders. The ADIS-IV was used to determine group psychiatric status. The ADIS-IV has demonstrated good inter-rater reliability $(\mathrm{k} \geq 0.81)$ for $\mathrm{PD}(26,27)$. 
Asthma, panic disorder and $\mathrm{CO}_{2}$

\section{Asthma Control Questionnaire (ACQ)}

The ACQ (28) is a 7-item self-report questionnaire that is designed to measure asthma control levels by assessing asthma symptoms, activity limitations, and bronchodilator use in the past week. An example item is: "In general, during the past week, how limited were you in your daily activities because of your asthma?". Patients rank each item on a 7-point scale $(0=$ good control, 6 = poor control), where higher scores indicate worse control. Finally, the lab technician completed the question on spirometry results assessing predicted $\mathrm{FEV}_{1}$.

\section{Experimental measures}

\section{Panic Symptom Scale (PSS)}

The PSS (29) is a 13-item questionnaire that was administered as a structured interview by a trained $\mathrm{PhD}$ student in clinical psychology to assess panic symptomatology. This questionnaire, derived from the PA criteria listed in the DSM-III (which has not changed in the DSM-5), allows the patient to rank each panic symptom and its intensity on a 5-point Likert-like scale $(0=$ absent to $4=$ extremely severe $)$ and the total score indicates the number of symptoms $(\max =13)$, as well as the intensity $(\max =65)$ of the PA. A PA in response to the $\mathrm{CO}_{2}$ challenge was considered present when a participant endorsed the fear item on the PSS, plus at least 3 other items, at the end of the $\mathrm{CO}_{2}$ challenge (6).

\section{Borg Scale}

The Borg Scale (30) is a 12-point self-report scale designed to measure perceived breathlessness and is constructed to allow the patient to rate beyond 10, indicating maximal intensity. In the field of respiratory diseases, the Borg scale has shown good reliability and validity in adult populations (31). 
Asthma, panic disorder and $\mathrm{CO}_{2}$

\section{Subjective Distress Visual Analogue Scale (SD-VAS)}

The SD-VAS (32) is a widely used self-report questionnaire that measures a large variety of subjective characteristics. Patients were asked to rate their agreement to 3 statements on their level of anxiety, discomfort, and worry, by slashing a continuous horizontal line from 0 (not at all) to 100 (extremely). The SD-VAS total score was calculated by measuring the distance between the left side of the line to the level rated by the patient, where higher scores represent higher intensity. The SD-VAS has shown good reliability and validity (32).

\section{Statistical analyses}

To assess baseline differences between groups in sociodemographic, medical, asthma, and psychological characteristics, general linear models (GLM) were used, with partial eta squares used as effect sizes $\left(\eta^{2}\right)$. A similar two-group GLM was used to evaluate our first hypothesis, the relationship between PD and PA status and bronchoconstriction. In order to test for significant main or interaction effects of group and time on subjective distress, and respiratory and physiological responses, a series of two-group (PD/PA and noPD/noPA) x two-time (baseline and post- $\mathrm{CO}_{2}$ ) repeated measures mixed model regressions were used to evaluate our second and third hypotheses. Age, sex, and provocative concentration of methacholine $\left(\mathrm{PC}_{20}\right.$ : a measure of bronchial responsiveness and proxy for asthma severity) were included as a-priori covariates in all the analyses, as per the CONSORT and Psychosomatic Medicine guidelines, due to their established influences on the main outcome variables $(33,34) . \mathrm{F}^{2}$ was used as a measure of effect size per previous work (35). Significance was set at .05 and data analyses were performed using SAS v9.4 (SAS Institute, Cary NC). 
Asthma, panic disorder and $\mathrm{CO}_{2}$

\section{RESULTS}

\section{Sample characteristics}

A total of 25 adult asthma patients were included in the present study. The mean age of the sample was 45 years $(\mathrm{SD}=15), 84 \%(\mathrm{n}=21)$ were female, and $52 \%(\mathrm{n}=13)$ were cohabitating with a partner. Patients had a mean of 15 years of education $(\mathrm{SD}=3)$, and $80 \%(\mathrm{n}=$ 20) were employed. They were on average overweight (mean measured body mass index [BMI] $\left.\mathrm{kg} / \mathrm{m}^{2}: \mathrm{M}=27.7, \mathrm{SD}=5.7\right)$, and $48 \%(\mathrm{n}=12)$ were past smokers. Patients had a mean $\mathrm{FEV}_{1} \%$ predicted of 97 , forced vital capacity (FVC) of 106 , and a $\mathrm{FEV}_{1} / \mathrm{FVC}$ of 83 . On average, participants had asthma for 20 years $(\mathrm{SD}=14)$ and were prescribed an average daily dose of inhaled corticosteroid (ICS) of $590 \mu \mathrm{g}$ fluticasone equivalent (SD = 529). The mean score on the ACQ was $1.03(\mathrm{SD}=0.89)$, denoting moderately poorly controlled asthma (28).

Table 1 shows the sociodemographic, clinical, asthma-related, and psychological characteristics of the participants as a function of PD and PA diagnosis. Participants in the PD/PA group had a diagnosis of asthma for a significantly longer period of time in comparison to those in the noPD/noPA group. There were no other significant differences between groups.

\section{Association between PD and PA status and objective airway obstruction}

Adjusted analyses showed no main effects of group (mean \% [SD]: PD/PA = 93 [2], noPD/noPA $=88[2], F=2.19, \mathrm{p}=.156)$, a trend for an effect of time $(\mathrm{F}=3.06, \mathrm{p}=.093)$, and no group by time interaction $\left(\mathrm{F}=0.35, \mathrm{p}=.558, \mathrm{f}^{2}=0.01\right)$, indicating that both groups had similar $\mathrm{FEV}_{1}$ and there was a similar trend for $\mathrm{FEV}_{1}$ changes in response to $\mathrm{CO}_{2}$ across both groups. When measuring the association between PD and PA status and bronchial response, both groups had a similar number of participants that experienced $\mathrm{a} \geq 10 \%$ drop in their $\mathrm{FEV}_{1}$ post challenge $\left(\%\right.$ participants $[\mathrm{n}]: \mathrm{PD} / \mathrm{PA}=27[4] ;$ noPD/noPA $=10[1], \mathrm{F}=0.94, \mathrm{p}=.344$, partial $\left.\eta^{2}=0.04\right)$, 
Asthma, panic disorder and $\mathrm{CO}_{2}$

as well as similar overall $\mathrm{FEV}_{1}$ drops (mean \% drop of $\mathrm{FEV}_{1}[\mathrm{SD}]: \mathrm{PD}=8$ [8]; No $\mathrm{PD}=5$ [4], F $=0.48, \mathrm{p}=.479$, partial $\left.\eta^{2}=0.023\right)$, indicating that having a PA did not have a statistically significant effect on bronchoconstriction.

\section{Association between PD and PA status and subjective distress}

Table 2 shows the results of the adjusted subjective distress analyses. There was a significant difference between groups for all variables, showing that PD/PA patients had more panic symptoms and worse anxiety, discomfort, worry, and dyspnea compared to noPD/noPA patients, regardless of time. Adjusted analyses also revealed that, across both groups, the panic challenge resulted in increased panic symptoms and worse anxiety, discomfort, worry, and dyspnea. Interaction effects were also found for several subjective distress variables, which illustrated that, in response to the $\mathrm{CO}_{2}$ challenge, PD/PA patients reported an elevated number of panic symptoms, worse anxiety, worry, and dyspnea compared to noPD/noPA patients (see Figure 2).

\section{Association between PD and PA status and cardiovascular activation}

Table 3 shows the results of the adjusted cardiovascular activation analyses. These indicated that there was no significant difference between groups for HR, SBP, and DBP, regardless of time. Additionally, only SBP was significantly higher at post-inhalation, regardless of group. No significant interaction effects were observed.

\section{Association between PD and PA status and respiratory responses}

Table 4 shows the results of the adjusted respiratory responses analyses. These revealed that there were no significant main effects for group or time on respiratory responses. However, 
Asthma, panic disorder and $\mathrm{CO}_{2}$

three significant interaction effects were found, where PD/PA patients experienced higher levels of $\mathrm{VCO}_{2}, \mathrm{VE}$, and $\mathrm{VT}$ at post-test compared to noPD/noPA patients (see Figure 3).

As reported in the supplemental material, a different pattern of results was observed when patients were assessed as a function of having/not having a PA, regardless of their PD diagnosis, where only a main effect of time for $\mathrm{VCO}_{2}, \mathrm{VE}$ and $\mathrm{VT}$ were observed, but no significant interaction effect (see supplement).

\section{DISCUSSION}

The present study investigated bronchoconstriction and subjective distress responses to a standard panic challenge in a well characterized sample of asthmatics with PD who had a PA, and those without PD who did not have a PA. Our hypotheses were partially supported: PD patients who had a PA after one vital capacity inhalation of $35 \% \mathrm{CO}_{2}$ exhibited elevated levels of subjective distress (i.e., symptoms of panic, anxiety, worry, and dyspnea) and increased respiratory responses (i.e., $\mathrm{VCO}_{2}, \mathrm{VE}$, and $\mathrm{VT}$ ), but not worse bronchoconstriction nor cardiovascular activation (i.e., HR and SBP/DBP) compared to asthmatics without PD who did not have a PA. To our knowledge, this is the first study to objectively assess both bronchoconstriction and subjective response to a simulated PA in asthmatics with versus without PD.

Contrary to our hypotheses, our results showed no difference in absolute levels of bronchoconstriction, as both groups exhibited similar levels of $\mathrm{FEV}_{1}$ after the challenge. Though not statistically significant, PD/PA patients were more than twice as likely to experience clinically significant bronchoconstriction (defined as a having a $\geq 10 \%$ drop in their $\mathrm{FEV}_{1}$ post challenge) than noPD/noPA patients. This suggests that PAs may be associated with an increased risk for clinically significant bronchoconstriction under conditions of acute stress, possibly due to 
Asthma, panic disorder and $\mathrm{CO}_{2}$

a hyperreactive central (autonomic) nervous system that may increase the risk for hyperventilation $(36,37)$. However, this effect did not reach statistical significance in our study, possibly due to sample size (low power), and as such is only speculative at this time.

Consistent with previous reports, this study showed increased subjective and respiratory responses following a $35 \% \mathrm{CO}_{2}$ challenge for $\mathrm{PD} / \mathrm{PA}$ patients, even in the absence of any objectively measured change in airway obstruction (38), which gives further support to the cognitive/affective theory linking PD with worse asthma outcomes (20). Indeed, PAs are often characterized by hyperventilation, which may be viewed as a compensatory phenomenon to an overly sensitive "suffocation alarm system" in PD patients (39). When a patient's $\mathrm{CO}_{2}$ partial pressure rises, the system starts firing at an abnormally low threshold, which may produce a cascade of respiratory-related symptoms. These changes could possibly be misinterpreted as lifethreatening asthma symptoms and trigger catastrophic fears about physiological sensations that are routinely experienced during a PA, which lead PD patients to overreact to normal physiological variations in breathing (40). This, in turn, can lead to a vicious cycle where the overreaction to normal bodily sensations stimulates an increase in somatic symptoms, which confirms their original catastrophic thought (41). Nonetheless, severe asthma attacks may provide legitimate cause for patient concern and be sufficient to produce hypersensitivity to respiratory sensations, which then serve as conditioned stimuli of anxiety-induced hyperventilation and panic $(2,42,43)$.

From a neural control perspective, PD patients having a PA may have abnormally elevated respiratory responses, as seen in the current study (i.e., VT, VE), which indicates that breathing regulation may be dysfunctional $(44,45)$. Although, it seems like the sensation of suffocation plays a central role in both disorders, in asthma it could be considered a "true" alarm triggered by bodily sensations related to an abnormality of peripheral respiratory mechanisms. 
Asthma, panic disorder and $\mathrm{CO}_{2}$

Conversely in PD, it has been suggested to be a "false" alarm related to a dysfunctional “suffocation alarm system" $(39,46)$. Interestingly, the supplemental analysis comparing patients that had a PA to those who did not have a PA regardless of their PD status demonstrated that the pattern of respiratory responses no longer showed any significant interaction effect but only a main effect of time for $\mathrm{VCO}_{2}, \mathrm{VE}$ and $\mathrm{VT}$, reflecting this tendency of hyperventilation to rebalance the $\mathrm{O}_{2}$ uptake and $\mathrm{CO}_{2}$ elimination. These additional findings illustrate an adjustment to the $\mathrm{CO}_{2}$ challenge (i.e., time effect) without observing any differentiating effects of group, which suggests that only PD patients experience abnormally elevated respiratory responses to the $\mathrm{CO}_{2}$ compared to participants that would have had a PA regardless of their mental state (see supplemental material). This further supports the importance of having PA's in the context of PD rather than just PAs alone.

Our findings are consistent with other cognitive/affective theory studies demonstrating no correlation between subjective distress and objective measures of asthma (47-50), but differ from those supporting a psychophysiological pathway suggesting that anxiety and mood disorders are associated with increased asthma or cardiovascular symptomatology (51-53). Nonetheless, our findings are clinically relevant since hypocapnia induced by hyperventilation, experienced during a patient's daily life, creates cognitive and respiratory symptoms that asthma patients cannot control using asthma medication, which could adversely affect their perception of control over the management of their disease (54). This could result in over-use of medication (i.e., shortacting bronchodilators) and increased health service use $(7,8)$.

The present study has some limitations that should be considered when interpreting the results. First, patients were recruited from a single tertiary care outpatient clinic, which is made up of moderate-severe asthma patients, so our study would generalize to a similar population but not necessarily asthmatics treated in the community. In addition, the study sample was selective 
Asthma, panic disorder and $\mathrm{CO}_{2}$

(e.g., exclusion of individuals with PD who are non-panicking) to answer the research questions and to obtain a well characterized sample. Second, our sample size was relatively small $(\mathrm{n}=25)$, and is possible that a larger sample size may have increased power to detect a significant difference because of observed small effect size, especially regarding our findings on bronchoconstriction (partial $\eta^{2}$ of 0.02 for overall drop in $\mathrm{FEV}_{1}$ post challenge and of 0.04 for experienced $\mathrm{a} \geq 10 \%$ drop in their $\mathrm{FEV}_{1}$ post challenge). Given the aversive nature of the study protocol, getting asthma patients with PD to participate voluntarily to experience a simulated PA was a challenge. To address the possibility of selection bias, we performed additional analyses (see Supplement) to verify if the pattern of results changed if we looked at the effects of having a PA (or not) regardless of PD status and we observed a similar pattern of results. This increases our confidence in the generalizability of the findings. Third, it has been suggested that the use of $\mathrm{CO}_{2}$ to induce PAs may not be optimal because the concentrations used are higher than concentrations present during a "natural" PAs (55) and due to potential bronchodilatory effects of $\mathrm{CO}_{2}$ (56). However, $\mathrm{CO}_{2}$ inhalation tends to induce PAs that are milder and end quicker (i.e., when the inhalation is finished) than 'natural' PAs (57), suggesting that our results represent at worst, conservative estimates of the true effect of naturally occurring panic attacks, which remain difficult to reproduce experimentally. Further, $\mathrm{CO}_{2}$ has been repeatedly shown to reliably induce PAs in similar experimental settings $(12,21,57,58)$. While it is true that $\mathrm{CO}_{2}$ may induce hypercapnia, which is associated with bronchodilatation, this tends to be observed in subjects with hypercapnia that is stable for at least 10 minutes. In our study, hypercapnia was only temporary (seconds to one minute maximum) as subjects inhaled only one vital capacity inhalation of a gas mixture containing $35 \% \mathrm{CO}_{2}$ (balanced with $\mathrm{O}_{2}$ ) and then breathed room air. Thus, we are confident that exposures in our study were not long enough to induce bronchodilation and significantly obscure any changes in bronchoconstriction. However, it would 
Asthma, panic disorder and $\mathrm{CO}_{2}$

be interesting to replicate our findings with another panicogenic substance. Fourth, one potential limitation and an area for future research would be to use other lung function measures (e.g., airway resistance, oscillatory resistance) to assess the impact of acute stress on bronchoconstriction which are more sensitive than spirometry (59). We chose to measure bronchoconstriction using spirometry, because of its clinical relevance and make our results accessible and meaningful to clinicians (60) who treat asthma and often struggle with differentiating asthma from panic/anxiety. However, it does raise the prospect that spirometry may have under-estimated the effect of panic disorder and panic attacks on bronchoconstriction. Future work should aim to use more sensitive measures of lung function to address this potential limitation. Fifth, the clinical research assistant assessing panic symptoms using the PSS was not blind to the psychiatric status of patients and this may have introduced some bias. However, the PSS was administered as a structured interview and scoring was done separately by computer. In addition, patients were blind to which gas they would get $\left(\mathrm{CO}_{2}\right.$ or $\mathrm{O}_{2}$, even though they all got $\mathrm{CO}_{2}$ ), which minimizes any potential subjective bias by the clinical research assistant. In addition, the ADIS-IV was conducted by a single student, so specific inter-rater reliability information is not available for this study. However, it was administered by a trained $\mathrm{PhD}$-level graduate student with 3 years of experience that was supervised by an experienced psychologist. Finally, we did not assess patients' perceptions about whether or not they were experiencing a panic or asthma attack during the $\mathrm{CO}_{2}$ challenge, which limits the understanding of the impact of the cognitive interpretation on the findings.

Despite these limitations, the present study also has a number of important strengths. First, this study makes a novel contribution to the existing literature by being the first, to our knowledge, to use a standardized and reliable panic challenge (one vital capacity inhalation of $35 \% \mathrm{CO}_{2}$ ) to assess bronchoconstriction and subjective responses in a well-characterized sample 
Asthma, panic disorder and $\mathrm{CO}_{2}$

of objectively diagnosed asthmatics with versus without interview-derived PD. Second, we included objective measures of pulmonary function (i.e., $\mathrm{FEV}_{1}$ ), as well as many other objective measures of respiratory and physiological responses, in order to assess specific and generalized arousal during a PA. Finally, we used a validated and reliable interview to assess PD and rule out any history of psychiatric disorders (i.e., ADIS-IV), and based PA diagnoses on DSM criteria.

In conclusion, this study improves our understanding of the role of PAs on objective airway obstruction, subjective and respiratory distress, and cardiovascular activation in asthmatics with and without PD. Having a PA in reaction to $\mathrm{CO}_{2}$ was associated with elevated subjective distress and respiratory responses, but not with bronchoconstriction or cardiovascular activation, which suggests that PAs may exacerbate asthma via predominantly cognitive/affective mechanisms, though studies with larger samples are needed to replicate and confirm these findings. In addition, it would be interesting to conduct another study that uses qualitative interviews to deepen our understanding of symptom perception. Clinical trials should be considered to assess the impact of treating PD using validated strategies such as cognitive behaviour therapy on symptoms, ventilatory and airway obstruction in response to $\mathrm{CO}_{2}$. This could help direct treatment resources toward this subgroup of asthma patients who may be at greater risk for asthma exacerbation and morbidity as a result of their comorbid psychiatric status.

Acknowledgements: Direct funding support for this study was provided by the Fonds de la recherche du Québec - Santé (FRQS) (Investigator awards: KLL \& SLB; scholarship: MB), the Canadian Institutes of Health Research (CIHR) (Investigator awards: KLL \& SLB; scholarship: MB; postdoctoral fellowship: NJP - FRN: MFE 146764), and the FRQS Respiratory Health Network (scholarship: MB). Contributions: Conception and design: MB, KLL, SLB, AC, BT, AM; Analysis and interpretation: MB, SLB, KLL; Drafting the manuscript for important 
Asthma, panic disorder and $\mathrm{CO}_{2}$

intellectual content: MB, KLL, SLB, AC, BT, AM, NJP. The authors thank Jill Vandermeerschen, M.Sc. for her invaluable assistance with statistical analyses. 
Asthma, panic disorder and $\mathrm{CO}_{2}$

\section{REFERENCES}

1. Kessler RC, Chiu WT, Demler O, Walters EE. Prevalence, severity, and comorbidity of 12-month DSM-IV disorders in the National Comorbidity Survey Replication. Archives of General Psychiatry. 2005;62:617-27.

2. Carr RE. Panic disorder and asthma: Causes, effects and research implications. J Psychosom Res. 1998;44:43-52.

3. Feldman JM, Mayefsky L, Beckmann L, Lehrer PM, Serebrisky D, Shim C. Ethnic differences in asthma-panic disorder comorbidity. J Allergy Clin Immunol. 2010;125:760-2.

4. Nascimento I, Nardi AE, Valenca AM, Lopes FL, Mezzasalma MA, Nascentes R, Zin WA. Psychiatric disorders in asthmatic outpatients. Psychiatry Res. 2002;110:73-80.

5. Shavitt RG, Gentil V, Mandetta R. The association between panic/agoraphobia and asthma. Contributing factors and clinical implications. Gen Hosp Psychiatry. 1992;14:420-3. 6. American Psychiatric Association. Diagnostic and statistical manual of mental disorders, fifth edition (DSM-5). Washington, DC: American Psychiatric Publishing; 2013.

7. Feldman JM, Lehrer PM, Borson S, Hallstrand TS, Siddique MI. Health care use and quality of life among patients with asthma and panic disorder. Journal of Asthma. 2005;42:17984.

8. Schneider A, Löwe B, Meyer FJ, Biessecker K, Joos S, Szecsenyi J. Depression and panic disorder as predictors of health outcomes for patients with asthma in primary care. Respir Med. 2008;102:359-66.

9. Favreau H, Bacon SL, Labrecque M, Lavoie KL. Prospective impact of panic disorder and panic-anxiety on asthma control, health service use, and quality of life in adult patients with asthma over a 4-year follow-up. Psychosomatic Medicine. 2014;76:147-55.

10. Hibbert G, Pilsbury D. Hyperventilation in panic attacks. Ambulant monitoring of transcutaneous carbon dioxide. The British Journal of Psychiatry. 1988;153:76-80.

11. Hibbert G, Pilsbury D. Demonstration and treatment of hyperventilation causing asthma. Br J Psychiatry. 1988;153:687-9.

12. Amaral JM, Spadaro PT, Pereira VM, Silva AC, Nardi AE. The carbon dioxide challenge test in panic disorder: a systematic review of preclinical and clinical research. Revista Brasileira de Psiquiatria. 2013;35:318-31.

13. Van Peski-Oosterbaan AS, Spinhoven P, Van der Does AJ, Willems LN, Sterk PJ. Is there a specific relationship between asthma and panic disorder? Behav Res Ther. 1996;34:333-40.

14. Griez EJ, Lousberg H, van den Hout MA, van der Molen GM. CO2 vulnerability in panic disorder. Psychiatry Res. 1987;20:87-95.

15. Papp LA, Klein DF, Gorman JM. Carbon dioxide hypersensitivity, hyperventilation, and panic disorder. Am J Psychiatry. 1993;150:1149-57.

16. van Beek N, Perna G, Schruers K, Verburg K, Cucchi M, Bellodi L, Griez E.

Vulnerability to $35 \% \mathrm{CO} 2$ of panic disorder patients with a history of respiratory disorders. Psychiatry Res. 2003;120:125-30.

17. Barlow DH. Anxiety and its disorders, second edition: the nature and treatment of anxiety and panic. New York, NY: The Guilford Press; 2002.

18. American Thoracic Society. Guidelines for methacholine and exercise challenge testing1999. Am J Respir Crit Care Med. 2000;161:309-29.

19. American Psychiatric Association. Diagnostic and statistical manual of mental disorders (4th ed., text revised). Washington, DC: American Psychiatric Association; 2000. 
Asthma, panic disorder and $\mathrm{CO}_{2}$

20. Boudreau M, Lavoie KL, Cartier A, Trutshnigg B, Morizio A, Lemière C, Bacon SL. Do asthma patients with panic disorder really have worse asthma? A comparison of physiological and psychological responses to a methacholine challenge. Respir Med. 2015;109:1250-6.

21. Fleet R, Lespérance F, Arsenault A, Grégoire J, Lavoie K, Laurin C, Harel F, Burelle D, Lambert J, Beitman B, Frasure-Smith N. Myocardial perfusion study of panic attacks in patients with coronary artery disease. The American Journal of Cardiology. 2005;96:1064-8.

22. Parsons JP, Hallstrand TS, Mastronarde JG, Kaminsky DA, Rundell KW, Hull JH, Storms WW, Weiler JM, Cheek FM, Wilson KC, Anderson SD, Bronchoconstriction ATSSoE-i. An official American Thoracic Society clinical practice guideline: exercise-induced bronchoconstriction. Am J Respir Crit Care Med. 2014;187:1016-27.

23. Knudson RJ, Lebowitz MD, Holberg CJ, Burrows B. Changes in the normal maximal expiratory flow-volume curve with growth and aging. American Review of Respiratory Disease. $1983 ; 127: 725-34$.

24. Miller MR, Hankinson J, Brusasco V, Burgos F, Casaburi R, Coates A, Crapo R, Enright P, van der Grinten CP, Gustafsson P, Jensen R, Johnson DC, MacIntyre N, McKay R, Navajas D, Pedersen OF, Pellegrino R, Viegi G, Wanger J, Force. AET. Standardisation of spirometry. The European Respiratory Journal. 2005;26:319-38.

25. Di Nardo PA, Brown TA, Barlow DH. Anxiety Disorders Interview Schedule for DSMIV: Lifetime version (ADIS-IV-L). San Antonio, TX: Psychological Corporation/Graywind Publications Inc; 1994.

26. Kessler RC, Chiu WT, Jin R, Ruscio AM, Shear K, Walters EE. The epidemiology of panic attacks, panic disorder, and agoraphobia in the National Comorbidity Survey Replication. Arch Gen Psychiatry. 2006;63:415-24.

27. Brown TA, Di Nardo PA, Lehman CL, Campbell LA. Reliability of DSM-IV anxiety and mood disorders: implications for the classification of emotional disorders. Journal of Abnormal Psychology. 2001;110:49-58.

28. Juniper EF, O'Byrne PM, Guyatt GH, Ferrie PJ, King DR. Development and validation of a questionnaire to measure asthma control. European Respiratory Journal. 1999;14:902-7.

29. Bradwejn J, Koszycki D, Shriqui C. Enhanced sensitivity to cholecystokinin tetrapeptide in panic disorder. Arch Gen Psychiatry. 1991;48:603-10.

30. Borg GA. Psychophysical bases of perceived exertion. Med Sci Sports Exerc. 1982;14:377-81.

31. Mahler DA, Mejia-Alfaro R, Ward J, Baird JC. Continuous measurement of breathlessness during exercise: validity, reliability, and responsiveness. J Appl Physiol. 2001;90:2188-96.

32. Wewers ME, Lowe NK. A Critical Review of Visual Analogue Scales in the Measurement of Clinical Phenomena. Res Nurs Health. 1990;13:227-36.

33. Moher D, Hopewell S, Schulz KF, Montori V, Gøtzsche PC, Devereaux PJ, Elbourne D, Egger M, Altman DG. CONSORT 2010 explanation and elaboration: updated guidelines for reporting parallel group randomised trials. Br Med J. 2010;14:c869. doi: 10.1136/bmj.c869.

34. Psychosomatic Medicine. Statistical Guidelines Checklist. 2006 [cited 2015 July 31]; Available from: http://journals.1ww.com/psychosomaticmedicine/Documents/Statistical\%20info.pdf.

35. Selya AS, Rose JS, Dierker LC, Hedeker D, Mermelstein RJ. A Practical Guide to Calculating Cohen's f(2), a Measure of Local Effect Size, from PROC MIXED. Front Psychol. 2012;3:111. 
Asthma, panic disorder and $\mathrm{CO}_{2}$

36. Hegel MT, Ferguson RJ. Psychophysiological assessment of respiratory function in panic disorder: evidence for a hyperventilation subtype. Psychosom Med. 1997;59:224-30.

37. Goodwin RD, Olfson M, Shea S, Lantigua RA, Carrasquilo O, Gameroff MJ, Weissman MM. Asthma and mental disorders in primary care. General Hospital Psychiatry. 2003;25:47983.

38. Steptoe A, Vogele C. Individual differences in the perception of bodily sensations: the role of trait anxiety and coping style. Behav Res Ther. 1992;30:597-607.

39. Klein DF. False suffocation alarms, spontaneous panics, and related conditions. An integrative hypothesis. Arch Gen Psychiatry. 1993;50:306-17.

40. Beck AT, Emery G, Greenberg RL. Anxiety disorders and phobias - A cognitive perspective. New York, NY: Basic Books; 1986.

41. Clark DM. A cognitive approach to panic. Behav Res Ther. 1986;24:461-70.

42. Isenberg SA, Lehrer PM, Hochron S. The effects of suggestion on airways of asthmatic subjects breathing room air as a suggested bronchoconstrictor and bronchodilator. J Psychosom Res. 1992b;36:769-76.

43. Hasler G, Gergen PJ, Kleinbaum DG, Ajdacic V, Gamma A, Eich D, Rössler W, Angst J. Asthma and panic in young adults: a 20 -year prospective community study. Am J Respir Crit Care Med. 2005;171:1224-30.

44. Gorman JM, Kent JM, Sullivan GM, Coplan JD. Neuroanatomical hypothesis of panic disorder, revised. Am J Psychiatry. 2000;157:493-505.

45. Nardi AE, Freire RC, Zin WA. Panic disorder and control of breathing. Respiraoty Physiology \& Neurobiology. 2009;167:133-43.

46. Klein DF. Testing the suffocation false alarm theory of panic disorder. Anxiety. 1994;1:17.

47. Fernandes L, Fonseca J, Martins S, Delgado L, Pereira AC, Vaz M, Branco G.

Association of anxiety with asthma: subjective and objective outcome measures. Psychosom Med. 2010;51:39-46.

48. Hayatbakhsh MR, Najman JM, Clavarino A, Bor W, Williams GM, O'Callaghan MJ. Association of psychiatric disorders, asthma and lung function in early adulthood. J Asthma. 2010;47:786-91.

49. Janson C, Björnsson E, Hetta J, Boman G. Anxiety and depression in relation to respiratory symptoms and asthma. Am J Respir Crit Care Med. 1994;149:930-4.

50. Nouwen A, Freeston MH, Labbé R, Boulet LP. Psychological factors associated with emergency room visits among asthmatic patients. Behav Modif. 1999;23:217-33.

51. Goodwin RD, Robinson M, Sly PD, McKeague IW, Susser ES, Zubrick SR, Stanley FJ, Mattes E. Severity and persistence of asthma and mental health: a birth cohort study. Psychol Med. 2013;43:1313-22.

52. McCauley E, Katon W, Russo J, Richardson L, Lozano P. Impact of anxiety and depression on functional impairment in adolescents with asthma. Gen Hosp Psychiatry. 2007;29:214-22.

53. Lavoie KL, Fleet RP, Laurin C, Arsenault A, Miller SB, Bacon SL. Heart rate variability in coronary artery disease patients with and without panic disorder. Psychiatry Res. 2004;128:289-99.

54. Ritz T, Rosenfield D, Meuret AE, Bobb C, Steptoe A. Hyperventilation symptoms are linked to a lower perceived health in asthma patients. Ann Behav Med. 2008;35:97-104.

55. McNally RJ, Hornig CD, Donnell CD. Clinical versus nonclinical panic: a test of suffocation false alarm theory. Behav Res Ther. 1995;33:127-31. 
Asthma, panic disorder and $\mathrm{CO}_{2}$

56. van den Elshout FJ, van Herwaarden CL, Folgering HT. Effects of hypercapnia and hypocapnia on respiratory resistance in normal and asthmatic subjects. Thorax. 1991;46:28-32. 57. Gorman JM, Kent J, Martinez J, Browne S, Coplan J, Papp LA. Physiological changes during carbon dioxide inhalation in patients with panic disorder, major depression, and premenstrual dysphoric disorder: evidence for a central fear mechanism. Arch Gen Psychiatry. 2001;58:125-31.

58. Blechert J, Wilhelm FH, Meuret AE, Wilhelm EM, Roth WT. Respiratory, autonomic, and experiential responses to repeated inhalations of $20 \% \mathrm{CO}_{2}$ enriched air in panic disorder, social phobia, and healthy controls. Biol Psychol. 2010;84:104-11.

59. Kaminsky DA. What does airway resistance tell us about lung function? Respir Care. 2011;57:85-96.

60. Global Inititative for Asthma. GINA Report, Global Strategy for Asthma Management and Prevention. 2014 [updated May 2014]; Available from:

http://www.ginasthma.org/local/uploads/content/files/StrategyBackgrounder.pdf. 
Asthma, panic disorder and $\mathrm{CO}_{2}$

Table 1: Participant sociodemographic, medical, asthma, and psychological characteristics.

\begin{tabular}{|c|c|c|c|c|c|}
\hline & $\begin{array}{l}\text { PD/PA } \\
(n=15)\end{array}$ & $\begin{array}{c}\text { noPD/noPA } \\
(n=10)\end{array}$ & $\mathbf{F}$ & $\mathbf{p}$ & $\eta^{2}$ \\
\hline \multicolumn{6}{|l|}{ Sociodemographics } \\
\hline Age (years) & $43 \pm 15$ & $47 \pm 15$ & 0.43 & .519 & 0.02 \\
\hline Sex (\% female $)$ & $94(14)$ & $70(7)$ & 2.48 & .129 & 0.10 \\
\hline Ethnicity (\% white) & $87(13)$ & $100(10)$ & 1.42 & .246 & 0.06 \\
\hline Cohabitating (\% yes) & $53(8)$ & $50(5)$ & 0.02 & .877 & 0.00 \\
\hline Education (years) & $15 \pm 3$ & $15 \pm 4$ & 0.08 & .779 & 0.00 \\
\hline Employed (\% yes) & $87(13)$ & $70(7)$ & 1.00 & .328 & 0.04 \\
\hline \multicolumn{6}{|l|}{$\begin{array}{l}\text { Medical and asthma } \\
\text { characteristics }\end{array}$} \\
\hline $\mathrm{PC}_{20}$ levels (geometric M [95\%CIs]) & $\begin{array}{c}0.47[0.15- \\
1.46]\end{array}$ & $\begin{array}{c}0.48[0.12- \\
1.95]\end{array}$ & 0.00 & .961 & 0.00 \\
\hline Measured BMI $\left(\mathrm{kg} / \mathrm{m}^{2}\right)$ & $27 \pm 5$ & $29 \pm 6$ & 0.75 & .396 & 0.03 \\
\hline Past smoker $(\%)$ & $47(7)$ & $50(5)$ & 0.02 & .877 & 0.00 \\
\hline Emergency visits (\% in the last year) & $13(2)$ & $0(0)$ & 1.42 & .246 & 0.06 \\
\hline Asthma duration (years) & $25 \pm 18$ & $13 \pm 7$ & 4.52 & $.045 *$ & 0.16 \\
\hline $\mathrm{FEV}_{1}(\%$ predicted $)$ & $99 \pm 12$ & $94 \pm 16$ & 0.86 & .363 & 0.04 \\
\hline FVC $(\%$ predicted $)$ & $110 \pm 12$ & $101 \pm 11$ & 3.97 & .058 & 0.15 \\
\hline $\mathrm{FEV}_{1} / \mathrm{FVC}(\%$ predicted $)$ & $90 \pm 2$ & $93 \pm 3$ & 0.07 & .795 & 0.00 \\
\hline ACQ score & $0.97 \pm 0.83$ & $1.11 \pm 1.02$ & 0.15 & .702 & 0.01 \\
\hline \multicolumn{6}{|l|}{ Medication use } \\
\hline ICS dose $(\mu \mathrm{g})$ & $\begin{array}{c}605.38 \pm \\
608.11\end{array}$ & $\begin{array}{c}428.57 \pm \\
228.47\end{array}$ & 1.03 & .320 & 0.00 \\
\hline
\end{tabular}


Asthma, panic disorder and $\mathrm{CO}_{2}$

\begin{tabular}{|l|c|c|c|c|c|}
\hline Combined LABA (\%) & $47(7)$ & $50(5)$ & 0.02 & .877 & 0.00 \\
\hline Beta-2 short action (\%) & $80(12)$ & $90(9)$ & 0.42 & .524 & 0.02 \\
\hline Any antidepressants (\%) & $47(7)$ & $10(1)$ & 4.00 & .057 & 0.15 \\
\hline Any anxiolytics (\%) & $20(3)$ & $0(0)$ & 2.30 & .143 & 0.09 \\
\hline
\end{tabular}

Note. Data are presented as $\mathrm{M} \pm \mathrm{SD}$ or percent (n). ACQ = Asthma Control Questionnaire; BMI

$=$ Body Mass Index FEV $_{1}=$ Forced Expiratory Volume in one second $; \mathrm{FVC}=$ Forced Vital

Capacity; ICS = Inhaled Corticosteroids; noPD/noPA = No Panic Disorder and No Panic Attack

group $\mathrm{PC}_{20}=$ Provocative Concentration of methacholine; PD/PA = Panic Disorder and Panic

Attack group.

Statistical test used: General linear models.

* Significant difference between the groups set at 0.05 
Asthma, panic disorder and $\mathrm{CO}_{2}$

Table 2: Effect of PD and PA status and time on subjective distress following a $35 \% \mathrm{CO}_{2}$ challenge.

\begin{tabular}{|c|c|c|c|c|c|c|c|c|c|c|c|}
\hline & \multicolumn{4}{|c|}{$\mathbf{M} \pm \mathrm{SD}$} & \multicolumn{4}{|c|}{ Main effects } & \multicolumn{3}{|c|}{ Interaction effect } \\
\hline & \multicolumn{2}{|c|}{ PD/PA } & \multicolumn{2}{|c|}{ noPD/noPA } & \multicolumn{2}{|c|}{$\begin{array}{c}\text { PD and PA } \\
\text { status }\end{array}$} & \multicolumn{2}{|c|}{ Time } & \multicolumn{3}{|c|}{ PD and PA $x$ time } \\
\hline & Pre-test & Post-test & Pre-test & Post-test & $\mathbf{F}$ & $\mathbf{p}$ & $\mathbf{F}$ & $\mathbf{p}$ & $\mathbf{F}$ & $\mathbf{p}$ & $\begin{array}{c}\mathbf{F}^{2} \text { for } \\
\text { interaction }\end{array}$ \\
\hline $\begin{array}{l}\text { PSS - Number of panic } \\
\text { symptoms }\end{array}$ & $\begin{array}{c}1.65 \pm \\
0.44\end{array}$ & $8.58 \pm 0.60$ & $\begin{array}{c}0.82 \pm \\
0.31\end{array}$ & $\begin{array}{l}3.62 \pm \\
0.52\end{array}$ & 33.32 & $<.001 *$ & 63.01 & $<.001 *$ & 18.10 & $<.001 *$ & 0.33 \\
\hline PSS - Total score $\dagger$ & $\begin{array}{l}5.80 \pm \\
0.71\end{array}$ & $7.16 \pm 1.47$ & $\begin{array}{l}7.01 \pm \\
0.78\end{array}$ & $\begin{array}{c}5.84 \pm \\
0.61\end{array}$ & 0.25 & .624 & 0.27 & .612 & 2.11 & .161 & 0.03 \\
\hline SD-VAS - Anxiety & $\begin{array}{l}8.66 \pm \\
3.61\end{array}$ & $\begin{array}{c}58.88 \pm \\
6.49\end{array}$ & $\begin{array}{l}1.12 \pm \\
1.62\end{array}$ & $\begin{array}{l}9.22 \pm \\
3.44\end{array}$ & 43.42 & $<.001 *$ & 24.63 & $<.001 *$ & 21.93 & $<.001 *$ & 0.35 \\
\hline SD-VAS - Discomfort & $\begin{array}{c}9.35 \pm \\
4.50\end{array}$ & $\begin{array}{c}62.43 \pm \\
8.45\end{array}$ & $\begin{array}{c}2.77 \pm \\
3.65\end{array}$ & $\begin{array}{c}35.67 \pm \\
7.34\end{array}$ & 7.91 & $.011^{*}$ & 48.99 & $<.001 *$ & 2.93 & .101 & 0.06 \\
\hline SD-VAS - Worry & $\begin{array}{l}6.50 \pm \\
2.51\end{array}$ & $\begin{array}{c}55.14 \pm \\
7.00\end{array}$ & $\begin{array}{l}2.16 \pm \\
1.94\end{array}$ & $\begin{array}{l}7.96 \pm \\
2.23\end{array}$ & 44.32 & $<.001 *$ & 22.90 & $<.001 *$ & 26.31 & $<.001 *$ & 0.41 \\
\hline Borg scale & $\begin{array}{l}1.20 \pm \\
0.51\end{array}$ & $5.91 \pm 0.89$ & $\begin{array}{c}0.93 \pm \\
0.39\end{array}$ & $\begin{array}{l}3.08 \pm \\
0.95\end{array}$ & 7.71 & $.012 *$ & 29.25 & $<.001 *$ & 4.68 & $.042 *$ & 0.09 \\
\hline
\end{tabular}

Note. noPD/noPA = No Panic Disorder and No Panic Attack group; PD/PA = Panic Disorder and Panic Attack group; PSS = Panic

Symptom Scale; SD-VAS = Subjective Distress Visual Analogue Scale. 
Asthma, panic disorder and $\mathrm{CO}_{2}$

$\dagger$ Adjusted for the number of panic symptoms on the PSS.

Statistical test used: Repeated measures mixed model regressions.

* Significant difference between the groups set at 0.05 
Asthma, panic disorder and $\mathrm{CO}_{2}$

Table 3: Effect of PD and PA status and time on cardiovascular responses following a $35 \% \mathrm{CO}_{2}$ challenge.

\begin{tabular}{|c|c|c|c|c|c|c|c|c|c|c|c|}
\hline & \multicolumn{4}{|c|}{$\mathbf{M} \pm \mathbf{S D}$} & \multicolumn{4}{|c|}{ Main effects } & \multirow{2}{*}{\multicolumn{3}{|c|}{$\begin{array}{l}\text { Interaction effect } \\
\text { PD and PA } x \text { time }\end{array}$}} \\
\hline & \multicolumn{2}{|c|}{ PD/PA } & \multicolumn{2}{|c|}{ noPD/noPA } & \multicolumn{2}{|c|}{$\begin{array}{l}\text { PD and PA } \\
\text { status }\end{array}$} & \multicolumn{2}{|c|}{ Time } & & & \\
\hline & Pre-test & Post-test & Pre-test & Post-test & $\mathbf{F}$ & $\mathbf{p}$ & $\mathbf{F}$ & $\mathbf{p}$ & $\mathbf{F}$ & $\mathbf{p}$ & $\begin{array}{c}\text { F2 for } \\
\text { interaction }\end{array}$ \\
\hline HR & $76.56 \pm 3.61$ & $79.52 \pm 3.35$ & $70.50 \pm 3.58$ & $72.40 \pm 3.32$ & 4.31 & .052 & 3.16 & .091 & 0.11 & .739 & 0.003 \\
\hline SBP & $120.33 \pm 3.08$ & $129.41 \pm 3.81$ & $121.14 \pm 3.42$ & $128.96 \pm 4.70$ & 0.00 & .975 & 9.48 & $.006^{*}$ & 0.04 & .837 & 0.001 \\
\hline DBP & $74.76 \pm 2.22$ & $80.70 \pm 2.25$ & $74.71 \pm 1.37$ & $76.65 \pm 2.72$ & 0.72 & .408 & 5.75 & .026 & 1.02 & .324 & 0.03 \\
\hline
\end{tabular}

Note. DBP = Diastolic Blood Pressure; HR = Heart Rate; PD = Panic Disorder; noPD/noPA = No Panic Disorder and No Panic Attack group; PD/PA = Panic Disorder and Panic Attack group; SBP = Systolic Blood Pressure.

Statistical test used: Repeated measures mixed model regressions.

* Significant difference between the groups set at 0.05 
Asthma, panic disorder and $\mathrm{CO}_{2}$

Table 4: Effect of PD and PA status and time on respiratory responses following a $35 \% \mathrm{CO}_{2}$ challenge.

\begin{tabular}{|c|c|c|c|c|c|c|c|}
\hline & \multicolumn{4}{|c|}{ Main effects } & \multicolumn{3}{|c|}{ Interaction effect } \\
\hline & \multicolumn{2}{|c|}{ PD and PA status } & \multicolumn{2}{|c|}{ Time } & \multicolumn{3}{|c|}{ PD and PA $x$ time } \\
\hline & $\mathbf{F}$ & $\mathbf{P}$ & $\mathbf{F}$ & $\mathbf{p}$ & $\mathbf{F}$ & $\mathbf{p}$ & $\mathbf{F}^{2}$ for interaction \\
\hline $\mathrm{VCO}_{2}$ & 0.71 & .398 & 1.21 & .271 & 5.89 & $.015^{*}$ & 0.05 \\
\hline $\mathrm{VO}_{2}$ & 0.03 & .865 & 0.68 & .401 & 3.03 & .082 & 0.06 \\
\hline VE & 3.43 & .064 & 1.45 & .228 & 4.48 & $.034 *$ & 0.07 \\
\hline VT & 0.09 & .765 & 1.41 & .235 & 4.62 & $.032 *$ & 0.06 \\
\hline $\mathrm{RR}$ & 4.55 & .033 & 0.79 & .374 & 0.45 & .502 & 0.06 \\
\hline
\end{tabular}

Note. noPD/noPA = No Panic Disorder and No Panic Attack group; PD/PA = Panic Disorder and Panic Attack group; RR = Respiratory rate (breaths/min); $\mathrm{VCO}_{2}=$ Carbon Dioxide production $(\mathrm{ml} / \mathrm{kg} / \mathrm{min}) ; \mathrm{VE}=$ Minute Ventilation $(\mathrm{L} / \mathrm{min}) ; \mathrm{VO} 2=\mathrm{Oxygen}$ Uptake $(\mathrm{ml} / \mathrm{kg} / \mathrm{min}) ; \mathrm{VT}=$ Tidal Volume $(\mathrm{L})$.

Statistical test used: Repeated measures mixed model regressions.

* Significant difference between the groups set at 0.05 
Asthma, panic disorder and $\mathrm{CO}_{2}$

Figure 1: Flow chart of patient screening, eligibility, and participation.

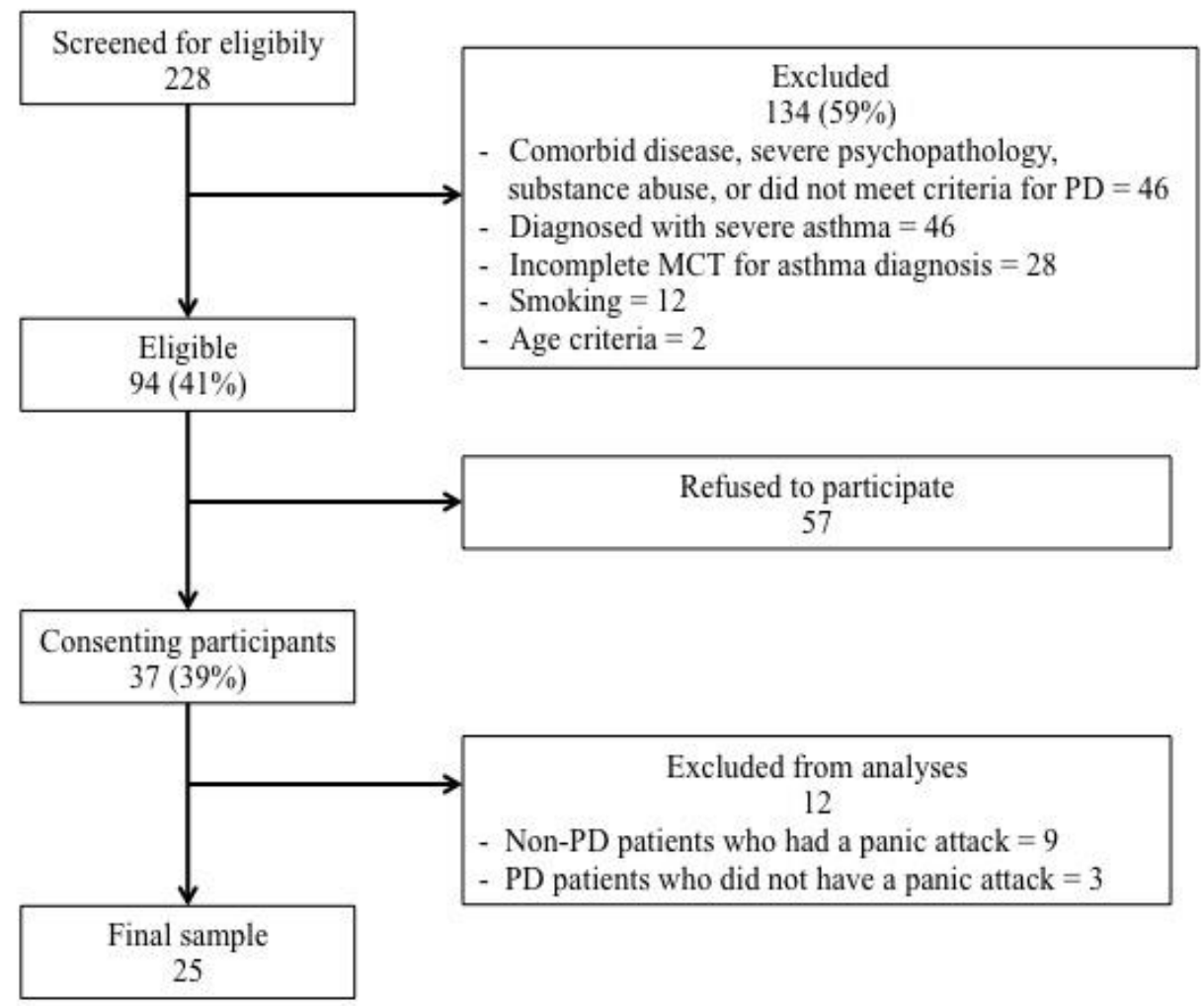


Asthma, panic disorder and $\mathrm{CO}_{2}$

Figure 2: Interaction effect of PD and PA status and time following a $35 \% \mathrm{CO}_{2}$ challenge on $\mathrm{A}$ ) the number of panic symptoms of PSS, B) anxiety on the VAS, C) worry on the SD-VAS, and D) Borg Scale.
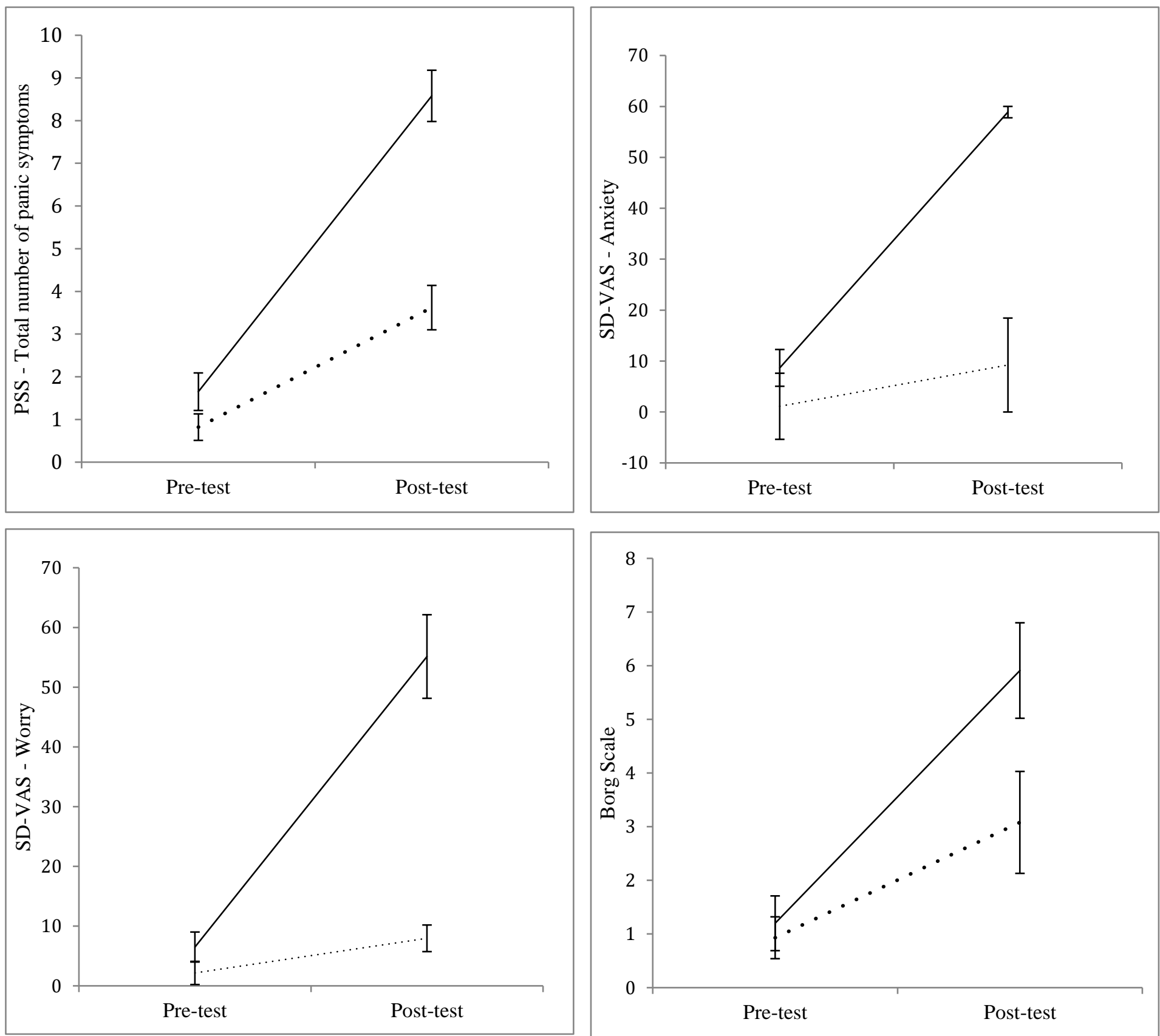

Note. noPD/noPA $($ dashed line $)=$ No Panic Disorder and No Panic Attack group; PD/PA (solid line $)=$ Panic Disorder and Panic Attack group; PSS = Panic Symptom Scale, SD-VAS = Subjective Distress Visual Analogue Scale. Presented as Means \pm S.E 
Asthma, panic disorder and $\mathrm{CO}_{2}$

Figure 3: Interaction effect of $\mathrm{PD}$ and PA status and time following a $35 \% \mathrm{CO}_{2}$ challenge on $\mathrm{A}$ ) $\left.\mathrm{VCO}_{2}, \mathrm{~B}\right) \mathrm{VE}$, and C) VT.

A

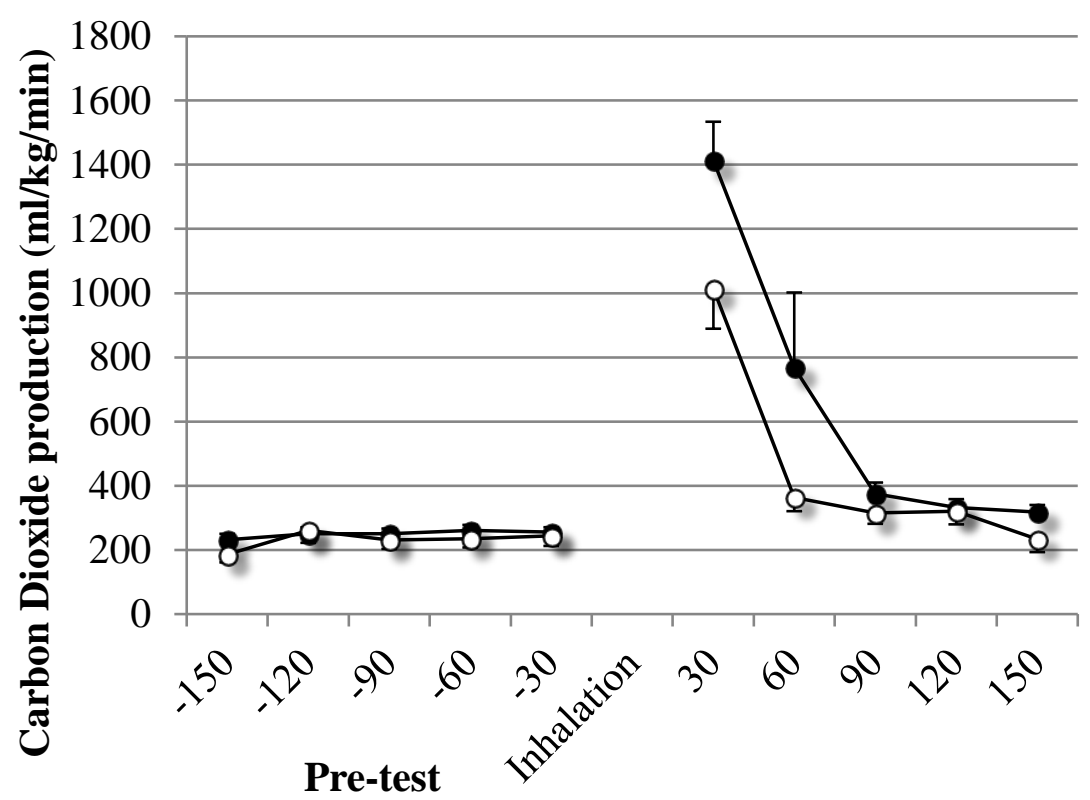

$\rightarrow \mathrm{PD} / \mathrm{PA}$

$\multimap-$ noPD/noPA

B

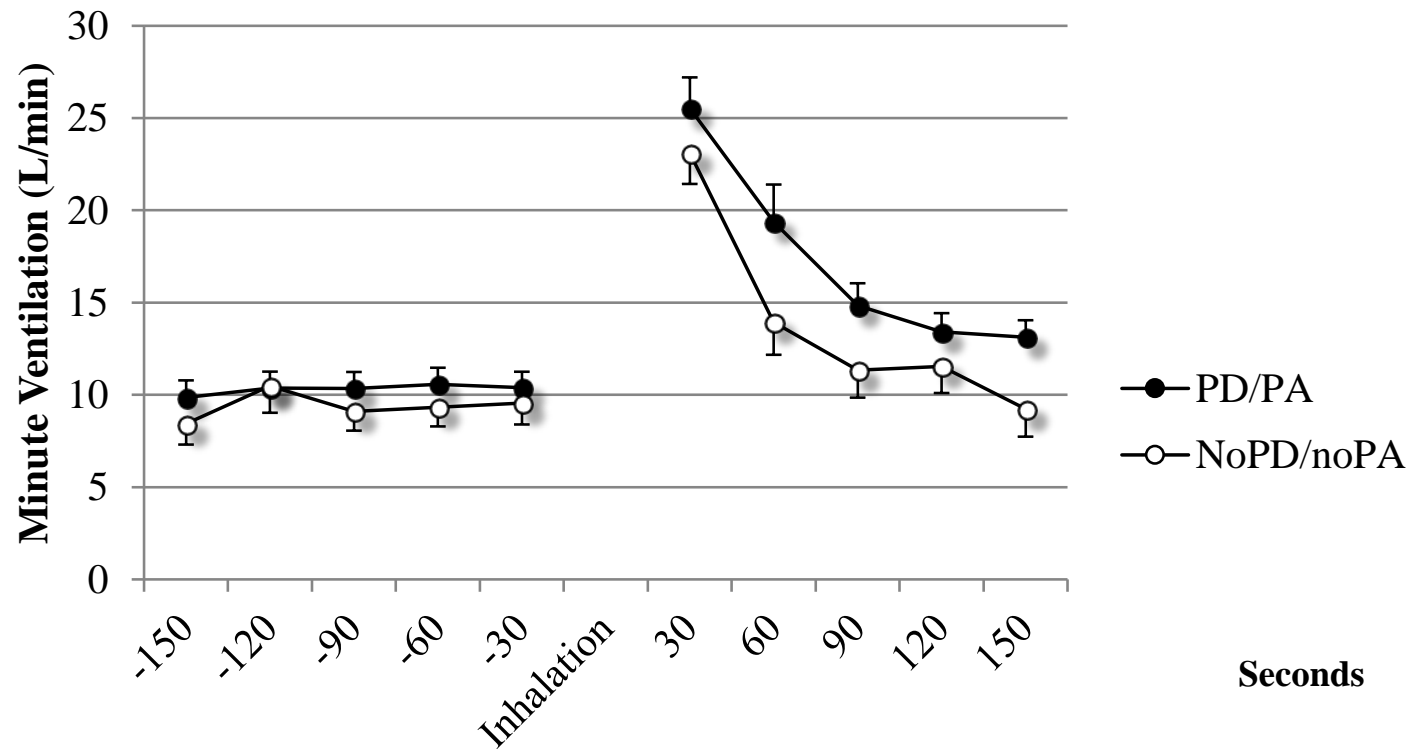

Pre-test

Post-test

Seconds

Post-test 
Asthma, panic disorder and $\mathrm{CO}_{2}$

C

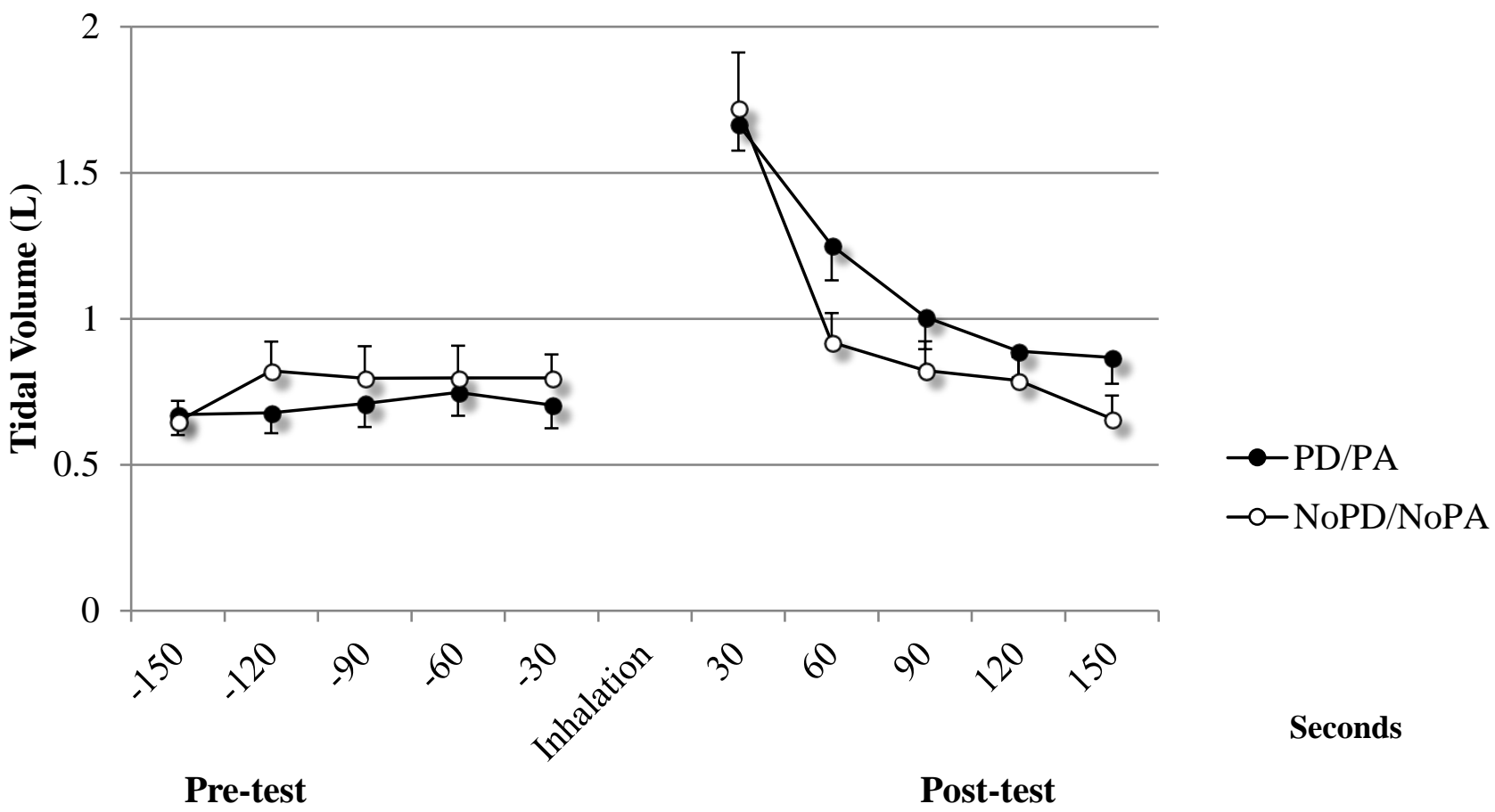

Note. noPD/noPA = No Panic Disorder and No Panic Attack group; PD/PA = Panic Disorder and Panic Attack group; $\mathrm{VCO}_{2}=$ Carbon Dioxide production; $\mathrm{VE}=$ Minute Ventilation; $\mathrm{VT}=$ Tidal Volume. 